\title{
Transition Networks in a Cohort of Patients with Congestive Heart Failure
}

\section{A novel application of informatics methods to inform care coordination}

J. A. Merrill'; B. M. Sheehan²; K. M. Carley3; P. D. Stetson ${ }^{4}$

${ }^{1}$ Columbia University Medical Center, New York, NY, United States; ${ }^{2}$ Division of Health and Life Sciences, Intel Corporation, Santa Clara, CA, United States; ${ }^{3}$ Institute of Software Research, Carnegie Mellon University, Pittsburgh, PN, United States; ${ }^{4}$ Memorial Sloan Kettering Cancer Center, New York, NY, United States

\section{Keywords}

Care coordination, patient care management, network analysis, heart failure, healthcare systems

\section{Summary}

Background: Unnecessary hospital readmissions are one source of escalating costs that may be reduced through improved care coordination, but how best to design and evaluate coordination programs is poorly understood. Measuring patient flow between service visits could support decisions for coordinating care, particularly for conditions such as congestive heart failure (CHF) which have high morbidity, costs, and hospital readmission rates.

Objective: To determine the feasibility of using network analysis to explore patterns of service delivery for patients with CHF in the context of readmissions.

Methods: A retrospective cohort study used de-identified records for patients $\geq 18$ years with an ICD-9 diagnosis code 428.0-428.9, and service visits between July 2011 and June 2012. Patients were stratified by admission outcome. Traditional and novel network analysis techniques were applied to characterize care patterns.

Results: Patients transitioned between services in different order and frequency depending on admission status. Patient-to-service CoUsage networks were diffuse suggesting unstructured flow of patients with no obvious coordination hubs. In service-to-service Transition networks a specialty heart failure service was on the care path to the most other services for never admitted patients, evidence of how specialist care may prevent hospital admissions for some patients. For patients admitted once, transitions expanded for a clinic-based internal medicine service which clinical experts identified as a Patient Centered Medical Home implemented in the first month for which we obtained data.

Conclusions: We detected valid patterns consistent with a targeted care initiative, which experts could understand and explain, suggesting the method has utility for understanding coordination. The analysis revealed strong but complex patterns that could not be demonstrated using traditional linear methods alone. Network analysis supports measurement of real world health care service delivery, shows how transitions vary between services based on outcome, and with further development has potential to inform coordination strategies. 


\section{Correspondence to:}

Jacqueline A Merrill, PhD, MPH, RN

Associate Professor of Nursing in Biomedical Informatics

Columbia University Medical Center

617 West 168th Street, Georgian 226

New York, New York 10034

Tel.: 2123053194

Email: jam119@columbia.edu
Appl Clin Inform 2015; 6: 548-564

http://dx.doi.org/10.4338/ACI-2015-02-RA-0021

received: February 27, 2015

accepted in revised form: July 10, 2015

published: September 2, 2015

Citation: Merrill JA, Sheehan BM, Carley KM, Stetson PD. Transition networks in a cohort of patients with congestive heart failure: a novel application of informatics methods to inform care coordination. Appl Clin Inform 2015; 6: 548-564

http://dx.doi.org/10.4338/ACI-2015-02-RA-0021 


\section{Introduction}

Care coordination is the deliberate organization of patient care activities to facilitate appropriate delivery of health care services [1]. Excess costs from poorly coordinated health care are estimated at 240 billion dollars per year [2,3]. Coordination is a critical precondition to achieving the nation's goals for quality improvement in healthcare [1,4-7]. However, there are profound gaps in our knowledge of how care coordination can be achieved. Interventions ranging from team-building to information technology have been studied, with mixed results that illustrate how little is known about designing or evaluating effective care coordination programs [8-11].

Care coordination is a recommended strategy for reducing readmissions in patients with congestive heart failure (CHF), a chronic condition associated with significant morbidity and cost $[12,13]$. Thirty-day hospital readmission rates in CHF are as high as 27\% [14-17]. Factors such as severity, comorbidities, and insurance are involved, but do not fully explain the issue [18-20]. Risk models are only slightly better than chance at predicting CHF readmissions [21], suggesting that unmeasured factors are involved [22].

Coordination is an "activity fundamentally about connections among interdependent actors who transfer information and other resources to achieve outcomes" [23]. In healthcare, information and resources flow through dynamic service delivery networks that can be shaped by purposeful organizational design [24]. Yet, organizational factors for preventing outcomes like unnecessary readmissions are poorly understood [25]. The degree of coordination across disciplines and services is not commonly measured $[14,21,26]$, making it difficult to assess any effects on quality and patient outcomes [27-32]. One approach to this problem could be examination of the flow of patients between services. If flow could be accurately measured it might identify patterns of care that influence outcomes and knowledge that could inform coordination efforts aimed at quality, cost, or suboptimal events like readmissions.

Network analysis is a non-linear technique that measures relationship interdependencies in social and organizational systems, which traditional statistical methods cannot capture [33]. The method combines mathematics and social science to detect and interpret patterns in relational data. A node in a network can represent any discrete entity, such as an individual or an event. Links indicate a relationship between nodes that can be measured and quantified. Data collected during the care process allows us to measure networks consisting of patients and the services they use. Such networks, interpreted in the context of outcomes, have potential to produce a deeper understanding of the dynamics of coordination across multiple care settings or integrated settings, like accountable care organizations (ACO) [34-36]. The resulting insights may inform interventions to optimize care delivery.

Although currently understudied, analysis of care patterns is considered a necessary first step for understanding variation in health care outcomes and a means for researchers, clinicians, and policy makers to evaluate service delivery, system characteristics, and emerging trends [37]. Recent studies have examined patterns in cancer care, social services, and chronic disease care [38-45]. Transitions between service settings have been measured [41, 44], but to our knowledge network analysis of these transitions has not been used.

\section{Objectives}

This exploratory study is an analysis of a de-identified, limited data set extracted from institutional databases. Our two-fold objective was 1) to investigate the flow of patients across ambulatory and inpatient services for evidence of care patterns, and 2) to determine the feasibility of using network analysis to measure and inform organizational strategies for care coordination. We measured networks of inpatient and outpatient clinical service visits made by CHF patients and described patterns of care in relation to the outcome of hospital admission/readmission. 


\section{Methods}

A retrospective cohort study was conducted using existing clinical and administrative data for patients treated within the Columbia University Medical Center (CUMC) system. The protocol was approved by the CUMC Institutional Review Board.

\subsection{Setting and Sample}

CUMC is comprised of: ColumbiaDoctors Faculty Practice Organization (FPO); NewYork-Presbyterian Hospital (NYP); and the NYP Ambulatory Care Network (ACN). The FPO delivers about 900000 ambulatory visits each year. NYP is a quaternary care hospital network with about 118000 discharges and about 1500000 outpatient visits per year. The NYP ACN delivers approximately 570000 visits per year. Patients transition among these three organizations with regularity through visits to primary and specialty care, emergency room, and hospital. The study was initiated by the FPO quality division.

\subsection{Data Sources and Variables}

A cohort was identified from the FPO electronic health record (EHR) problem list and cross-referenced with data from the registration, scheduling, and administrative billing system. Patients included were those 18 years and older with an ICD-9 diagnosis code 428.0-428.9 who had documentation on at least one outpatient visit with a ColumbiaDoctors provider between July 1, 2011 and June 30, 2012. We excluded patients for whom the etiology of CHF was congenital heart disease. The resulting list was used to obtain data from additional institutional data sources, including NYP inpatient and ambulatory administrative, scheduling, and billing systems.

The primary variable, service visit, was selected based on evidence suggesting that the visit history plays a significant role in heart failure readmissions [46]. Service visit types included all inpatient, emergency, and outpatient services and the date on which a visit was made by an individual patient to the FPO, NYP inpatient units, and the ACN. We cross mapped the formats used by each system to locate specific data elements. For inpatient visits, we obtained admission and discharge dates, admission diagnosis, and secondary diagnoses. Length of stay was calculated for inpatient stays. Descriptive variables included demographic information, insurance status and, for patients with hospital admissions, risk of mortality (ROM) and severity of illness (SOI) scores. After data merging, patient identifiers were stripped and birth dates altered. Dates of service delivery were retained.

The cohort was stratified into four sub groups by admission status: 1) Never Admitted; 2) Admitted Once, not readmitted; 3) Single Re-admit within 30 days of a discharge; and 4) Multiple Re-Admits within 30 days of a discharge. Single and Multiple Re-admits were identified by calculating the difference between a re-admission date for any cause and the previous discharge date.

\subsection{The Network Model}

Network analysis was used to characterize relationships between patients and clinical services. Both traditional network analysis and novel techniques developed for this study were applied. Our analysis was performed using ORA ${ }^{\oplus}$ software [47].

Our first step was to construct basic patient to service links to understand the distribution of direct links between patients and services in the four groups. We produced bipartite matrices consisting of rows representing individuals in our cohort and columns representing 113 discrete services they used. We defined a link in the network Uij to be 1 if patient i uses service j, else 0 . Next, we developed service CoUsage networks to understand the total volume of visits patient made between pairs of services regardless of when or the order in which they occurred. Using matrix algebra, we calculated co-usage of services by multiplying the transpose of $\mathrm{U}$ by itself, i.e., for patient $i$ of $\mathrm{N}$ patients, and services $j$ and $k$, co-usage is:

$$
\text { CoUsage }_{j k}=\sum_{i=1}^{N} U_{i j} * U_{i k}
$$


Lastly, to understand temporal frequency of visits we developed service-to-service Transition networks where the link weight is the fraction of all visits to service A followed by a visit to service B. We defined a network, $W_{i j}(t)$ where each link indicates that patient $i$ visited service $j$ at time $t$. We then calculated the transition from $j$ to $k$ by patient $i$ at time $t+1$, or $\operatorname{Tran}_{i j k}(t+1)$, as follows:

$$
\text { if } W_{i j}(t) \geq 1 \& W_{i k}(t+1) \geq 1 \text { then } \operatorname{Tran}_{i j k}(t+1)=1 \text {, else } \operatorname{Tran}_{i j k}(t+1)=0 \text {. }
$$

For $\mathrm{T}$ time periods, $\mathrm{N}$ patients, and $\mathrm{S}$ services the transition probability is defined as the conditional probability that given the patients visited service $\mathrm{j}$ they visited service $\mathrm{k}$ next:

$$
\frac{\sum_{i=1}^{N} \sum_{t=1}^{T} \operatorname{Tran}_{i j k}(t+1)}{\sum_{j=1}^{S} \sum_{i=1}^{N} \sum_{t=1}^{T} \operatorname{Tran}_{i j k}(t+1)}
$$

We standardized a transition probability for each link to allow comparison of groups by admission status. Since the vast number of service visits were on different days, this approach reflects transitions. The most frequent causes of same-day visit sequences were multiple visits to the same service (e.g. more than one encounter), or a laboratory and/or radiology visit on the same day as a visit to a clinical service. If a patient visited two or more services on the same day directionality was determined opportunistically, based on record number. While there is no guarantee record numbers correspond to time, this method is more likely than other ways of ordering, such as alphabetically.

To reduce noise and improve saliency of the analysis, the clinical researchers (JAM, BS, PDS) used domain expertise and iterative review to reduce the service node count. Services with the lowest transition probabilities and those judged more tangential to treatment of CHF were targeted. For example, dental, ophthalmology, ENT, and gastroenterology were consolidated to "Other Medical". Closely related services were collapsed into single classes (e.g. all obstetric services; inpatient and outpatient psychiatric services; all rehabilitation services). This produced 48 service classes.

A set of network measurements were calculated at the group level and, for a sub-set of service classes, at the node level. $>$ Table 1 gives definitions, interpretations, and formulas for the measures used. In the CoUsage networks the link values are counts representing the number of patients that visited both services. This allowed use of standard social network measures of centrality to identify prominent nodes (service classes). Unlike linear statistics, social network measurements are dependent observations [48]. In our networks there was almost perfect correlation between centrality measurements; for total degree, betweenness, eigenvector, and closeness, centrality coefficients ranged 0.98-0.99 across the four groups. Therefore, we report total degree centrality because we are mainly interested in finding nodes (service classes) that are prominent due to the number of patients that co-use them. The Transition networks are not typical because each link represents an order and a probability. Standard social network measures of centrality are not useful since they cannot be interpreted as a directed flow. To capture flow we calculated inverted betweenness centrality to find nodes that are prominent due to the sequence of paths that pass through them. This measure was moderately correlated with standard centrality measures; coefficients ranged $0.53-0.81$ across the groups, but we have explained that standard measures cannot be interpreted for transition links.

\subsection{Validation of the model}

Experts determined face validity of the analysis. Members of CUMC's Informatics Intervention Research Collaborative (I2RC) advised on the direction of the analysis at multiple points. This multidisciplinary group is comprised of senior faculty and investigators in Biomedical Informatics, Nursing, Psychiatry, Public Health, Internal Medicine, and Business. The group meets weekly to oversee and guide clinical informatics intervention studies, serving as a "core resource" of domain expertise for investigators. The final results and interpretation were reviewed in detail by senior leaders engaged in ColumbiaDoctors and NYP care coordination initiatives. All are active in programs including the Patient Centered Medical Home (PCMH) and Patient Centered Specialty Program, shared-risk programs with commercial insurers and Medicare, and a recently formed ACO. 


\section{Results}

There were 4803 patients who met the study criteria. A third of them (33.4\%) were Never Admitted to the hospital. Among those hospitalized, most (73\%) were only Admitted Once. About a quarter $(26.8 \%)$ were readmitted within 30 days of a previous discharge. Among the readmitted, two thirds (66\%) had a Single Re-admit and one third (34\%) had Multiple Re-admits. The cohort was older; means for the groups ranged between 68-75 years. The three hospitalized groups had similar risk of mortality and severity of illness scores. There was a slightly higher proportion of males in the Never Admitted and Admitted Once groups (60.5\% and 54.9\% respectively), but in the two readmitted groups, gender was evenly distributed. White was the most frequent race/ethnicity across groups (range 29-41\%), although race/ethnicity was not specified for roughly half of the cohort. Medicare was the most frequent insurance carrier. The proportion of patients with Medicaid as their primary insurance was lowest in the Never Admitted group and highest in the Multiple Re-admit group (16\% vs. 5.8\%). These characteristics are summarized in $>$ Table 2.

\subsection{Network level measurements}

Network measurements are given in Table 3. The Admitted Once group is the largest, with the highest count of service visits (13026), and highest average patients per service class (844, range 1162).

In the patient to service networks, density measurements showed between $8 \%$ and $17 \%$ of possible links present, trending upward with group admission status. Individual patients visited between 1 and 22 of the 48 service classes, averaging $4-8$ by group, also trending upward with group admission status.

In the service CoUsage networks, density measurements showed between $73 \%$ and $89 \%$ of possible links between services present. The greatest density of service co-usage was in the Admitted Once group. Network diameter reflected a breadth of between 46 and 85 service transitions and was greatest in the Admitted Once group. There was no evidence of a centralized network structure in any group (0.04-0.05).

In the service to service Transition networks, density measurements showed that between $45 \%$ and $67 \%$ of possible service pairs had at least one patient transition between them. The greatest density of service to service transitions was in the Admitted Once group. Network diameters reflected a breadth of only 4 to 6 service transitions. There was no evidence of a centralized network structure in any group (0.03-0.04).

\subsection{Visualizations}

In $>$ Figure 1 visualizations of the Transition networks illustrate visually what is described quantitatively by the measurements. Link width increases with frequency of transitions between services. Links weighted $<0.10$ are hidden to improve the clarity of the image. The link default color is blue; red and green highlight two services that emerged with the highest inverted betweenness measurements across groups.

In $>$ Figure $1 \mathrm{~A}$, the Never Admitted group, the service node Heart Failure FPO has a prominent position. The width of links to and from the node and peripheral services (red links) reflect a care patterns of frequent transitions, particularly to and from Ambulatory Surgery and Heart Transplant, both of which are FPO services.

In Figure $1 \mathrm{~B}$, the Admitted Once group, the pattern changes markedly. Although the network has greater density $(0.67)$, many links have weights $<0.10$ and thus are not visible. The pattern appears more diffuse. Internal Medicine ACN (green) emerges as a distinct sub network with links to other clinic services that are part of the NYP ACN network. The width of the link between Emergency and Adult Medical Surgical reflects the frequency of transitions to the inpatient unit. The width of links to and from Heart Failure FPO and to and from Cardiology Diagnostics show key transitions in this care pattern.

In $>$ Figures $1 \mathrm{C}$ and $1 \mathrm{D}$, the Single and Multiple Admit group, the networks return to lower density $(0.47$ and 0.45$)$. The width of the links between the inpatient services, Adult Medical Surgical 
and Adult Critical Care, with Emergency and Cardiology Diagnostics shows a care pattern of frequent transitions along those paths. The Internal Medicine ACN node retains a distinct sub network position without direct transitions $(>0.10)$ with Heart Failure FPO or Cardiology Diagnostics.

\subsection{Node level analysis}

We selected a sub set of service classes for further investigation based upon the patterns found in the network analysis (higher ranked services) and the team's familiarity with the care process (potential sites for a coordinator). Table 4 shows the node level measurements for six service classes to illustrate how the link configurations in the CoUsage and Transition networks produce very different insights. In the CoUsage networks, total degree centrality ranged between 0.01-0.09 across groups. These low measurements with little variability did not detect any prominent service co-used with any others. In contrast, in the Transition networks the measurements were an order of magnitude higher for two services: Internal Medicine ACN (0.28-0.14) and Heart Failure FPO (0.54-0.27). These two services are prominent in the care patterns of all four groups. Low inverted betweenness for the other services indicates they are on fewer service paths, suggesting less potential as coordination points.

\section{Discussion}

This exploratory study used network analysis and a limited data set to explore transitions between services during a 12 month period for a cohort of 4803 patients with a diagnosis of CHF. It is the first study to our knowledge to use network analysis to describe patterns in patient service visits based on clinical and administrative data from a quaternary medical center. Our application of network metrics to a patient to service transition matrix is also, to our knowledge, unique.

\subsection{Evidence of care coordination across ambulatory and inpatient services}

Low network centralization in both the CoUsage and Transition networks indicates a diffuse care network, suggesting a relatively unstructured flow of patients among the services involved in CHF, with no dominant service or set of services in control. Higher density and diameter in the CoUsage networks shows that nearly every possible pair of services is co-used by at least one patient, and as a whole this cohort of patients visits a broad range of services. Moderate density and smaller diameter in the transition networks, however, suggests that individual patients frequent a small number of services in sequence, and this is echoed by the low service class per patient ratio.

Our analysis showed that CHF patients transition between services in distinctly different order and frequency according to their admission status. The Admitted Once group in particular shows a care pattern distinct from the other three groups. In this group there are many more transitions and $>50 \%$ increase in links between services (density) compared to the Never Admitted group, suggesting an expanded care pattern that initiates with an admission. In the Single and Multiple Re-admit groups, however, density drops suggesting a contracted or more focused care pattern, likely in response to acuity that resulted in readmission.

Inverted betweenness measurements in the transition networks for a subset of six service classes found Heart Failure FPO is an important transition point. This makes sense for two reasons: first, it is the service that targets heart failure, including pre and post-transplant care; and second, because the study was initiated by the FPO, the cohort was initially drawn from FPO data. The cohort also tended to use Internal Medicine ACN in conjunction with more service classes, in effect creating care paths from these two services on to many others. However, there is an interesting difference: Internal Medicine ACN appears as a coordinating waypoint more for patients with one or more admission, denoted by a doubling in inverted betweenness in the Admitted Once group compared to Never Admitted. The clinical experts explained that, on admission to NYP, patients with a CHF diagnosis become registered in an ACN-managed $\mathrm{PCMH}$ and are targeted for comprehensive management that center on ACN services: internal medicine, anti-coagulation, social services, and nutri- 
tion and wound care. It appears that Heart Failure FPO serves this function for Never Admitted patients, as its inverted betweenness drops by nearly half in the three admitted groups. This may be evidence of how management by heart failure specialists is preventing hospital admissions for some patients, a hypothesis which deserves further investigation.

The findings have potential to inform care coordination initiatives at our institution. CUMC has an operational PCMH for CHF and recently launched an ACO targeting CHF. The network positions of Internal Medicine ACN and Heart Failure FPO show them as key entities in different care patterns. For example, Internal Medicine ACN has transitions links with Social Services and Nutrition, but these transitions are missing to/from Heart Failure FPO. Some FPO patients may be referred to these services outside the CUMC system, there may be patients receiving CHF care for whom additional services are needed, or there may be other explanations.

We detected an expanding pattern of transitions in the Admitted Once group and increased co-usage and centrality associated with the Internal Medicine ACN. The clinical experts confirmed that these results are consistent with the "intensive care-management" program implemented in July of 2011, the first month for which we obtained data. The results of this program's effect on hospital readmissions for patients with $\mathrm{CHF}$ are published elsewhere [49]. Although our data originated with FPO patients, there was a surprising level of utilization of ACN services. This raises interesting organizational issues--why and when do FPO patients use NYP services, and vice versa, and are there opportunities for economies? An intervention expanding the PCMH registry to include patients managed by the Heart Failure FPO specialists prior to hospitalization, and coordinating interventions across the ACN and FPO, could ensure access to a broader range of services earlier and might mitigate some admissions. Nurse care managers who can cross organizational boundaries is one way to achieve this.

\subsection{Feasibility of using network analysis to measure and potentially in- form strategies for care coordination}

We found that network analysis can support measurement of real world health care utilization, quantify how CHF patients use services, and show how transitions between services vary with admission status. The analysis revealed strong, but not simple patterns. There was not a linear flow directed from any set of services. Instead, we found a complex web of linkages that could not be analyzed using traditional linear methods alone. The complexity of these data implicitly violates the independence assumptions for valid regression models due to the high potential for multi-collinearity $[24,50,51]$.

Our transition link configuration moves network analysis to a dynamic framework that captures movement of patients within a care network. Relational links between services based on co-usage alone can mislead because they represent static relationships. Likewise, network measures that give a node prominence based on a direct link count do not capture patient flow, whereas links based on transitions denote patient progression between services. Inverted betweenness centrality then reflects the degree to which a service node acts as a bridge along the path between other services [52], incorporating the concept of movement through transition points that degree centrality misses.

This kind of analysis is new but it has potential to produce actionable information. For example, among patients ever admitted a discharge from in-patient Adult Critical Care had 65\% probability of a transition to Cardiology Diagnostics, with only $6 \%$ probability of a transition to Emergency. In contrast, a discharge from in-patient Adult Medical-Surgical had $60 \%$ probability of transition to Emergency, followed by $30 \%$ probability of a transition to Cardiology Diagnostics, with $44 \%$ probability of return visits. Our experts explained: sicker patients (often referred for quaternary care) were discharged from Critical Care and likely received more specialty care and follow up; less sick patients discharged from Medical Surgical at that time (2011-12) were likely local residents who frequently used Emergency as a path to access services. Both phenomena have policy implications; in fact, emergency over-use has been amended [49]. While these observations do not emerge in traditional statistical analysis, they could be used to manage resources, to identify coordination opportunities like inefficient Emergency use, and evaluate the outcomes of coordination interventions. Further, the sub networks we found around Internal Medicine ACN and Heart Failure FPO gave insight into possible missing or duplicative services. This is valuable knowledge for care integration, 
as such services could be targets for consolidation or a system for managing over and underutilized services. Although not conclusive, our preliminary work also showed differences in care patterns based on characteristics such as age and insurance status. Development of the method to produce reliable real-time knowledge on care patterns could support planning, population-level coordination interventions, and even staffing.

\subsection{Limitations}

This is preliminary work that has several limitations. The data are from a large university medical center; the method is generalizable to similar environments where data are available to document patient flow among affiliated service settings. The data represent a sub set of CHF patients in the CUMC system and do not include care transitions outside the system. We did not analyze care delivered to our cohort by other health care facilities in our area, which may affect the outcomes we examined. Our data were limited to a single year. Based on the scope of our examination, we did not detect if patients had hospital admissions or service use prior to or after the study timeframe. There were considerable "unknown" services in our data due to naming inconsistencies in legacy data systems. Most were resolved but $1.2 \%$ remained unidentified. The link value calculations were manually programmed and may not reflect accurate directionality in all cases. The main reason is that date of service, not time, is marked in the underlying data; if a patient received three services in one day there was no way to be sure of the sequence actually followed.

\section{Conclusion}

Our analysis demonstrates proof of concept for the value of network analysis in the care coordination arena. We detected valid patterns consistent with a targeted care coordination initiative, which experts could understand and explain, suggesting the method has utility for measuring coordination. Our analysis produced insights that have potential to inform organizational strategies for care coordination. This study extends the scope of previous network studies of care transitions using claims data that do not reflect the temporal structure of care $[23,53]$.

There are several avenues for additional investigation. Future work will explore finer grained temporal indicators and/or methods to control for same day multi-service visits. Replication of the approach in larger data sets is merited, perhaps incorporating EHR workflow events, in addition to the service events studied here. We elected to study relationships at the group level versus the individual patient level. Although not conclusive, our early exploratory work suggests there will be variation in care patterns based on individual attributes such as age or comorbidities. This promising line of inquiry could allow us to prospectively identify optimal care trajectories for individuals. We plan to expand the scope of the analysis to patient populations with other chronic conditions. We also hope to expand our data set longitudinally and to access data from regional health information exchange organizations to capture visits to community care providers such as home care services, or other health care facilities to see the behaviors of whole populations, as that is what is required by new care models. It should also be noted that general Lab and Radiology services were also prominent in our Transition networks. We suspect this would be common in most chronic conditions, and not unique to CHF. A more comprehensive data set will allow us to explore such phenomena and their implications. Interventional research may include an examination of the network prior to the initiation of a care management program to evaluate change and build evidence for validity of the method.

\section{Clinical Relevance Statement}

Care coordination is a recommended strategy for improving health care quality and reducing costs, but little is known about how to design effective coordination programs or evaluate their effects. This study used network analysis to uncover patterns in how CHF patients use services, and detected valid care patterns which clinical experts could understand and explain, suggesting the method has utility for measuring coordination. With further development the method has potential for informing organizational strategies for care coordination. 


\section{Conflict of Interest}

At the time of the study PDS was CIO/CMIO at ColumbiaDoctors Faculty Practice and BS was Director of Quality Informatics. The other authors declare no conflicts of interest.

\section{Human Subjects Protection}

The study was performed in compliance with the World Medical Association Declaration of Helsinki on Ethical Principles for Medical Research Involving Human Subjects, and study protocols were approved by the institutional review board of CUMC. 

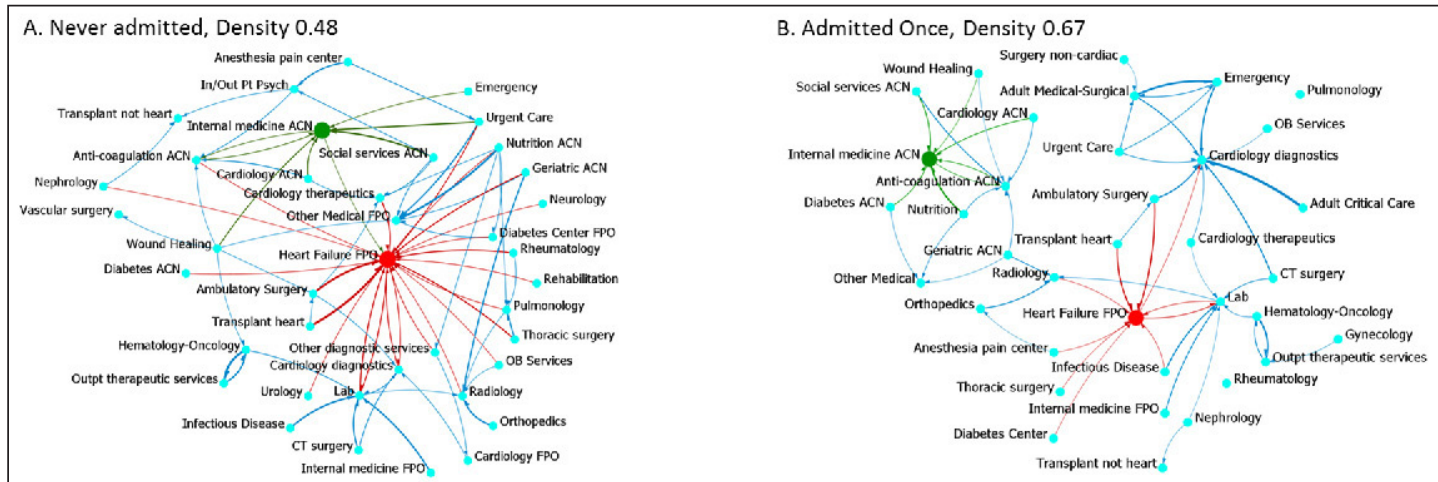

C. Single Readmit, Density 0.47
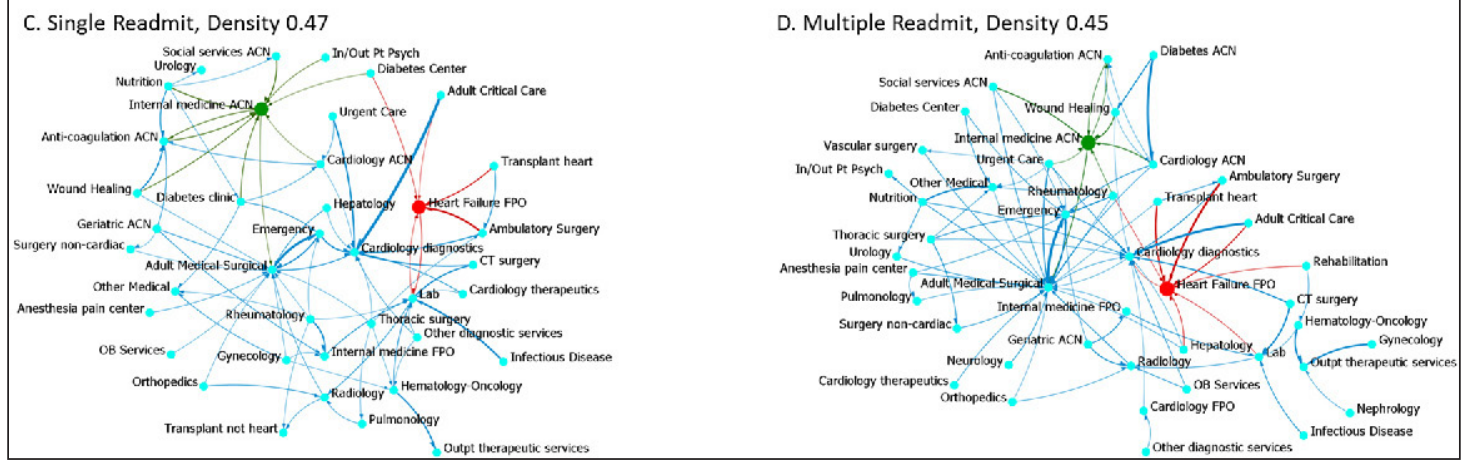

Fig. 1 Visualization of the service to service Transition networks. Links are weighted by transition probability. Links with transition probability $<0.10$ were removed to improve clarity of the images. Red and green coloration is used to emphasize two clinical service nodes with high inverted betweenness and their adjacent links. 
Table 1 Network measures with definitions, interpretations and equations'.

\begin{tabular}{|c|c|c|c|}
\hline $\begin{array}{l}\text { Group } \\
\text { level } \\
\text { measures }\end{array}$ & Definition & Interpretation & Equation \\
\hline $\begin{array}{l}\text { Centraliz- } \\
\text { ation } \\
\text { (normalized } \\
\text { range 0-1) }\end{array}$ & $\begin{array}{l}\text { Total number of direct } \\
\text { links to and from each } \\
\text { service to all others di- } \\
\text { vided by the maximum } \\
\text { possible sum of differ- } \\
\text { ences (e.g. if each service } \\
\text { classes had a single link } \\
\text { to one service class, and } \\
\text { could only have one link, } \\
\text { centralization = 1) }\end{array}$ & $\begin{array}{l}\text { Determines the degree to } \\
\text { which patient visits are organ- } \\
\text { ized around a core service or } \\
\text { set of services. Higher scores } \\
\text { mean more a hierarchical net- } \\
\text { work, while lower scores mean } \\
\text { a more diffuse network }\end{array}$ & $\frac{1-\sum_{i=1}^{N}\left|(N-1) * m-\sum_{j=1, j \neq i}^{N} X_{i j}\right|}{(N *(N-1) * m)}$ \\
\hline $\begin{array}{l}\text { Density } \\
\text { (normalized } \\
\text { range 0-1) }\end{array}$ & $\begin{array}{l}\text { Ratio of existing links be- } \\
\text { tween nodes versus all } \\
\text { links possible (e.g. if every } \\
\text { service class shared a } \\
\text { transition with every } \\
\text { other service class density } \\
\text { would be 1) }\end{array}$ & $\begin{array}{l}\text { Determines the degree of con- } \\
\text { nection between services. } \\
\text { Higher scores mean the net- } \\
\text { work is more of a well-inte- } \\
\text { grated whole in which more of } \\
\text { the services are connected to } \\
\text { each other, while lower scores } \\
\text { means less integration or } \\
\text { cohesion }\end{array}$ & $\left(\sum_{i=1}^{N} \sum_{j=1, j \neq i}^{N} X_{i j}\right) /_{N * N * m}$ \\
\hline $\begin{array}{l}\text { Diameter } \\
\text { (whole } \\
\text { number) }\end{array}$ & $\begin{array}{l}\text { The longest of all shortest } \\
\text { paths between pairs of } \\
\text { services }\end{array}$ & $\begin{array}{l}\text { Determines the longest possi- } \\
\text { ble sequences of services that } \\
\text { have been visited }\end{array}$ & $\max _{1 \leq i, j \leq N} S_{i j}$ \\
\hline $\begin{array}{l}\text { Node } \\
\text { level } \\
\text { measures }\end{array}$ & Definition & Interpretation & Equations \\
\hline $\begin{array}{l}\text { Total degree } \\
\text { centrality } \\
\text { (normalized } \\
\text { range } 0-1 \text { ) }\end{array}$ & $\begin{array}{l}\text { The sum of row and col- } \\
\text { umn degrees for each ser- } \\
\text { vice, reflecting the quan- } \\
\text { tity of links a single ser- } \\
\text { vice has to and from } \\
\text { other services, normalized } \\
\text { to go between } 0 \text { and } 1\end{array}$ & $\begin{array}{l}\text { Determines which service } \\
\text { classes are prominent in the } \\
\text { network by virtue of the } \\
\text { number of links associated } \\
\text { with them. A service or service } \\
\text { class that scores higher has } \\
\text { more direct links to other } \\
\text { services and likely is more } \\
\text { involved in what is happening } \\
\text { in the network }\end{array}$ & $\left(\sum_{i=1}^{N} X_{i j}+\sum_{j=1}^{N} X_{i j}\right) /_{(2 * N)}$ \\
\hline $\begin{array}{l}\text { Inverted be- } \\
\text { tweenness } \\
\text { centrality } \\
\text { (normalized } \\
\text { range 0-1) }\end{array}$ & $\begin{array}{l}\text { Betweenness centrality is } \\
\text { the proportion of transi- } \\
\text { tions linking pairs of ser- } \\
\text { vice classes that pass } \\
\text { through a service class of } \\
\text { interest. The inverted cal- } \\
\text { culation }\left(1 / X_{i j}\right) \text { is used * }\end{array}$ & $\begin{array}{l}\text { Determines services on a criti- } \\
\text { cal path for many patient tran- } \\
\text { sitions between services. A } \\
\text { service or service class that } \\
\text { scores higher has greater po- } \\
\text { tential to coordinate the flow } \\
\text { of patients between services }\end{array}$ & $\begin{array}{l}\sum_{i, j} \frac{X S_{i k j}}{X S_{i j}} \\
\text { Calculated using as link weights } \\
\frac{1}{X_{i j}}\end{array}$ \\
\hline
\end{tabular}

${ }^{1}$ In this table, $\mathrm{X}=$ a network with row $\mathrm{i}$ and column $\mathrm{j} ; \mathrm{N}=$ the number of nodes; $\mathrm{m}=$ the maximum link weight; $\mathrm{S}_{\mathrm{ij}}=$ the length of the geodesic (shortest path, between $\mathrm{i}$ and $\mathrm{j}$ ); $\mathrm{XS}_{\mathrm{ij}}=$ the number of geodesics (shortest paths) between $\mathrm{i}$ and $\mathrm{j}$; $\mathrm{XS}_{\mathrm{ikj}}=$ the number of those paths that pass through node $\mathrm{k}$.

${ }^{*}$ The betweenness centrality calculation equates link weight with distance from the end point nodes, thus higher link weight would result in a lower betweenness, inferring less potential for a service class (node) to influence flow in the network. Given that the links weights represent transition frequency not distance, the inverted calculation more accurately reflects that higher value links infer more potential for a service class to influence flow. 
Table 2 Demographic characteristics of 4803 CHF patients grouped by admission status.

\begin{tabular}{|c|c|c|c|c|c|}
\hline \multicolumn{2}{|l|}{ Group } & \multirow{2}{*}{$\begin{array}{l}\text { Never } \\
\text { Admitted } \\
1605\end{array}$} & \multirow{2}{*}{$\begin{array}{l}\text { Admitted } \\
\text { Once } \\
2341\end{array}$} & \multirow{2}{*}{$\begin{array}{l}\text { Single } \\
\text { Re-admit } \\
566\end{array}$} & \multirow{2}{*}{$\begin{array}{l}\text { Multiple } \\
\text { Re-admit } \\
291\end{array}$} \\
\hline Number of patients & & & & & \\
\hline \multirow[t]{3}{*}{ Age in years } & mean & 68 & 73 & 75 & 72 \\
\hline & median & 69 & 75 & 77 & 72 \\
\hline & range & 23-100 & $21-100$ & 24-100 & 23-100 \\
\hline \multirow[t]{2}{*}{ Gender \% } & Male & 60.5 & 54.7 & 49.8 & 49.5 \\
\hline & Female & 39.5 & 45.3 & 50.1 & 50.5 \\
\hline \multirow{6}{*}{$\begin{array}{l}\text { Race/ } \\
\text { Ethnicity \% }\end{array}$} & White & 41 & 37 & 37 & 29 \\
\hline & Black/African American & 9 & 11 & 11 & 10 \\
\hline & Asian & 2 & 0.8 & $6(1)$ & 0.3 \\
\hline & Hispanic/Latino & 0.8 & 0.4 & 0.2 & 0.7 \\
\hline & Other & 0.7 & 0.2 & 0.4 & 0.3 \\
\hline & Unknown/Declined & 47 & 51 & 51 & 59.7 \\
\hline \multirow[t]{6}{*}{ Insurance \% } & Medicare & 58 & 67 & 72 & 63 \\
\hline & Medicaid & 5.8 & 10.8 & 11.5 & 16 \\
\hline & Private & 33 & 16 & 11.7 & 12.8 \\
\hline & Self-pay & 0.5 & 0.7 & 0.3 & 0 \\
\hline & International & 0.4 & 0.6 & 0.2 & 0.3 \\
\hline & Unknown & 2 & 4.7 & 4 & 6.8 \\
\hline \multirow[t]{2}{*}{ ROM Score* } & mean & - & 2 & 2 & 2 \\
\hline & median & - & 2 & 2 & 2 \\
\hline \multirow[t]{2}{*}{ SOI SCORE* } & mean & - & 2 & 2 & 2 \\
\hline & median & - & 3 & 3 & 3 \\
\hline
\end{tabular}

- -not available, scores calculated at first hospital admission. * calculated using the $3 \mathrm{M}^{\mathrm{TM}}$ system 
Table 3 Network measurements for 4803 CHF patients grouped by admission status.

\begin{tabular}{|c|c|c|c|c|}
\hline & $\begin{array}{l}\text { Never } \\
\text { Admitted }\end{array}$ & $\begin{array}{l}\text { Admitted } \\
\text { Once }\end{array}$ & $\begin{array}{l}\text { Single } \\
\text { Re-admit }\end{array}$ & $\begin{array}{l}\text { Multiple } \\
\text { Re-admit }\end{array}$ \\
\hline \multicolumn{5}{|l|}{ Patient to service network } \\
\hline Patient count & 1605 & 2341 & 566 & 291 \\
\hline Service class count & 48 & 48 & 48 & 48 \\
\hline Link count & 6267 & 13,026 & 3735 & 2336 \\
\hline Density* & 0.08 & 0.12 & 0.14 & 0.17 \\
\hline Service classes/patient (Range, SD) & $4(1-16.3)$ & $6(1-21.3)$ & $7(2-22.3)$ & $8(2-22.4)$ \\
\hline Patients/ service class (SD) & $421(737)$ & $844(1162)$ & $301(438)$ & $238(376)$ \\
\hline \multicolumn{5}{|l|}{ Service CoUsage network } \\
\hline Density* & 0.73 & 0.89 & 0.79 & 0.78 \\
\hline Diameter & 53 & 85 & 46 & 57 \\
\hline Centralization* & 0.04 & 0.05 & 0.05 & 0.05 \\
\hline \multicolumn{5}{|c|}{ Service-to-service transition network } \\
\hline Density* & 0.48 & 0.67 & 0.47 & 0.45 \\
\hline Diameter & 6 & 5 & 5 & 4 \\
\hline Centralization* & 0.03 & 0.04 & 0.03 & 0.03 \\
\hline
\end{tabular}

* Density and centralization measurements are normalized between 0-1.

Table 4 Node level measurements for a subset of service classes in the CoUsage and Transition networks contrasts the results produced by metrics specific to the link configurations.

\begin{tabular}{|l|l|l|l|l|l|l|l|l|} 
Network Measure & \multicolumn{3}{l}{$\begin{array}{l}\text { Total degree centrality in } \\
\text { CoUsage networks }\end{array}$} & \multicolumn{4}{l}{$\begin{array}{l}\text { Inverted betweenness in } \\
\text { Transition networks }\end{array}$} \\
\hline Admission status & Never & Once & Single & Multiple & Never & Once & Single & Multiple \\
\hline Internal Medicine FPO & 0.03 & 0.03 & 0.02 & 0.02 & 0.00 & 0.00 & 0.02 & 0.00 \\
\hline Internal Medicine ACN & 0.04 & 0.06 & 0.03 & 0.05 & 0.14 & 0.28 & 0.21 & 0.20 \\
\hline Social Services ACN & 0.02 & 0.02 & 0.01 & 0.01 & 0.00 & 0.00 & 0.00 & 0.00 \\
\hline Heart Failure FPO & 0.09 & 0.06 & 0.04 & 0.06 & 0.54 & 0.28 & 0.27 & 0.27 \\
\hline Cardiology ACN & 0.02 & 0.03 & 0.02 & 0.04 & 0.00 & 0.00 & 0.00 & 0.02 \\
\hline Cardiology FPO & 0.03 & 0.03 & 0.02 & 0.02 & 0.02 & 0.00 & 0.00 & 0.00 \\
\hline Anti-coagulation ACN & 0.03 & 0.05 & 0.01 & 0.03 & 0.05 & 0.03 & 0.03 & 0.00 \\
\hline
\end{tabular}




\section{References}

1. McDonald K, Sundaram V, Bravata D, Lewis R. Closing the Quality Gap: A Critical Analysis of Quality Improvement Strategies No. 9.7 ed. Vol. 7, Care Coordination. Rockville, MD: Agency for Healthcare Research and Quality 2007. p. 3, Definitions of Care Coordination and Related Terms.

2. Institute of Medicine. The Healthcare Imperative: Lowering Costs and Improving Outcomes: Workshop Series Summary. In: Yong PL; Saunders RS; Olsen LA, editors. Vol. 3 Inefficiently Delivered Services, Roundtable on Evidence-Based Medicine Washington, DC: National Academies Press; 2010.

3. Institute of Medicine. Best Care at Lower Cost: The Path to Continuously Learning Health Care in America. Washington, DC: National Academy of Sciences; 2012.

4. Guterman S, Davis K, Schoenbaum S, Shih A. Using Medicare Payment Policy To Transform The Health System: A Framework For Improving Performance. Health Aff 2009; 28(2): w238-w250.

5. Landon BE, Keating NL, Barnett ML, Onnela JP, Paul S, O’Malley AJ, Keegan T, Christakis NA. Variation in patient-sharing networks of physicians across the United States. JAMA 2012; 308(3): 265-273.

6. National Quality Forum. Effective Communication and Care Coordination [cited 2015 February 9]. Available from: http://www.qualityforum.org/Topics/Effective_Communication_and_Care_Coordination.aspx

7. Agency for Healthcare Research and Quality (AHRQ). National Strategy for Quality Improvement in Health Care. Rockville, MD: Department of Health and Human Services; 2011.

8. Asaro PV, Sheldahl AL, Char DM. Embedded guideline information without patient specificity in a commercial emergency department computerized order-entry system. Acad Emerg Med 2006; 13(4): 452-458.

9. Handler JA, Feied CF, Coonan K, Vozenilek J, Gillam M, Peacock PR, Sinert R, Smith MS. Computerized physician order entry and online decision support. Acad Emerg Med 2004; 11(11): 1135-1141.

10. Press MJ, Michelow MD, MacPhail LH. Care coordination in accountable care organizations: moving beyond structure and incentives. Am J Manag Care 2012; 18(12): 778-780.

11. Agency for Healthcare Research and Quality (AHRQ). Closing the quality gap: A critical analysis of quality improvement strategies. Rockville, MD.: AHRQ; 2007.

12. Heidenreich PA, Albert NM, Allen LA, Bluemke DA, Butler J, Fonarow GC, Ikonomidis JS, Khavjou O, Konstam MA, Maddox TM, Nichol G, Pham M, Pina IL, Trogdon JG. Forecasting the Impact of Heart Failure in the United States: A Policy Statement From the American Heart Association. Circ Heart Fail 2013; 6(3): 606-619.

13. Takeda A, Taylor SJ, Taylor RS, Khan F, Krum H, Underwood M. Clinical service organisation for heart failure. Cochrane Database Syst Rev 2012; 9: CD002752.

14.Dharmarajan K, Hsieh AF, Lin Z, Bueno H, Ross JS, Horwitz LI, Barreto-Filho JA, Kim N, Bernheim SM, Suter LG, Drye EE, Krumholz HM. Diagnoses and timing of 30-day readmissions after hospitalization for heart failure, acute myocardial infarction, or pneumonia. JAMA 2013; 309(4): 355-363.

15. Krumholz HM, Merrill AR, Schone EM, Schreiner GC, Chen J, Bradley EH, Wang Y, Wang Y, Lin Z, Straube BM, Rapp MT, Normand SL, Drye EE. Patterns of hospital performance in acute myocardial infarction and heart failure 30-day mortality and readmission. Circulation Cardiovascular quality and outcomes 2009; 2(5): 407-413.

16. Jencks SF, Williams MV, Coleman EA. Rehospitalizations among patients in the Medicare fee-for-service program. The New England journal of medicine 2009; 360(14): 1418-1428.

17. Ross JS, Chen J, Lin Z, Bueno H, Curtis JP, Keenan PS, Normand SL, Schreiner G, Spertus JA, Vidan MT, Wang Y, Wang Y, Krumholz HM. Recent national trends in readmission rates after heart failure hospitalization. Circ Heart Fail 2010; 3(1): 97-103.

18. Au AG, McAlister FA, Bakal JA, Ezekowitz J, Kaul P, van Walraven C. Predicting the risk of unplanned readmission or death within 30 days of discharge after a heart failure hospitalization. American heart journal 2012; 164(3): 365-372.

19. Coffey RM, Misra A, Barrett M, Andrews RM, Mutter R, Moy E. Congestive heart failure: who is likely to be readmitted? Medical care research and review MCRR 2012; 69(5): 602-616.

20. Wallmann R, Llorca J, Gomez-Acebo I, Ortega AC, Roldan FR, Dierssen-Sotos T. Prediction of 30-day cardiac-related-emergency-readmissions using simple administrative hospital data. International journal of cardiology 2013; 164(2): 193-200.

21. Ross JS, Mulvey GK, Stauffer B, Patlolla V, Bernheim SM, Keenan PS, Krumholz HM. Statistical models and patient predictors of readmission for heart failure: a systematic review. Arch Intern Med 2008; 168(13): 1371-1386.

22. Gwadry-Sridhar FH, Flintoft V, Lee DS, Lee H, Guyatt GH. A systematic review and meta-analysis of studies comparing readmission rates and mortality rates in patients with heart failure. Arch Intern Med 2004; 164(21): 2315-2320. 
23. Barnett ML, Christakis NA, O’Malley J, Onnela JP, Keating NL, Landon BE. Physician patient-sharing networks and the cost and intensity of care in US hospitals. Med Care 2012; 50(2): 152-160.

24. Ash JS, McCormack JL, Sittig DF, Wright A, McMullen C, Bates DW. Standard practices for computerized clinical decision support in community hospitals: a national survey. J Am Med Inform Assoc 2012; 19(6): 980-987.

25. Bright TJ, Wong A, Dhurjati R, Bristow E, Bastian L, Coeytaux RR, Samsa G, Hasselblad V, Williams JW, Musty MD, Wing L, Kendrick AS, Sanders GD, Lobach D. Effect of clinical decision-support systems: a systematic review. Ann Intern Med 2012; 157(1): 29-43.

26. Sochalski J, Jaarsma T, Krumholz HM, Laramee A, McMurray JJ, Naylor MD, Rich MW, Riegel B, Stewart S. What works in chronic care management: the case of heart failure. Health Aff 2009; 28(1): 179-189.

27. Phillips CO, Singa RM, Rubin HR, Jaarsma T. Complexity of program and clinical outcomes of heart failure disease management incorporating specialist nurse-led heart failure clinics. A meta-regression analysis. European journal of heart failure 2005; 7(3): 333-341.

28. de Bruin SR, Heijink R, Lemmens LC, Struijs JN, Baan CA. Impact of disease management programs on healthcare expenditures for patients with diabetes, depression, heart failure or chronic obstructive pulmonary disease: a systematic review of the literature. Health Policy 2011; 101(2): 105-121.

29. Nucifora G, Albanese MC, De Biaggio P, Caliandro D, Gregori D, Goss P, Miani D, Fresco C, Rossi P, Bulfoni A, Fioretti PM. Lack of improvement of clinical outcomes by a low-cost, hospital-based heart failure management programme. Journal of cardiovascular medicine 2006; 7(8): 614-622.

30. Savard LA, Thompson DR, Clark AM. A meta-review of evidence on heart failure disease management programs: the challenges of describing and synthesizing evidence on complex interventions. Trials 2011; 12: 194.

31.Smith B, Forkner E, Zaslow B, Krasuski RA, Stajduhar K, Kwan M, Ellis R, Galbreath AD, Freeman GL. Disease management produces limited quality-of-life improvements in patients with congestive heart failure: evidence from a randomized trial in community-dwelling patients. Am J Manag Care 2005; 11(11): 701-713

32.Feltner C, Jones C, Cené C, Zheng ZJ, Sueta C, Coker-Schwimmer E, Arvanitis M, Lohr K, Middleton J, Jonas D. Transitional Care Interventions To Prevent Readmissions for People With Heart Failure. Rockville, MD: Agency for Healthcare Research and Quality; 2014.

33. Borgatti SP, Foster PC. The Network Paradigm in Organizational Research: A Review and Typology. Journal of Management 2003; 29(6): 991.

34. Galbraith J. Designing Organizations: An Executive Briefing on Strategy,Structure, and Process. San Francisco, CA: Jossey-Bass; 1995.

35. Peikes D, Chen A, Schore J, Brown R. Effects of care coordination on hospitalization, quality of care, and health care expenditures among medicare beneficiaries: 15 randomized trials. JAMA 2009; 301(6): 603-618.

36. McClellan M, McKethan AN, Lewis JL, Roski J, Fisher ES. A National Strategy To Put Accountable Care Into Practice. Health Aff 2010; 29(5): 982-990.

37. Butler EN, Chawla N, Lund J, Harlan LC, Warren JL, Yabroff KR. Patterns of Colorectal Cancer Care in the United States and Canada: A Systematic Review. Journal of the National Cancer Institute Monographs 2013; 2013(46): 13-35.

38. Daly B, Olopade OI. A perfect storm: How tumor biology, genomics, and health care delivery patterns collide to create a racial survival disparity in breast cancer and proposed interventions for change. CA: A Cancer Journal for Clinicians 2015; 65(3): 221-238.

39.Lipscomb J, Yabroff KR, Hornbrook MC, Gigli A, Francisci S, Krahn M, Gatta G, Trama A, Ritzwoller DP, Durand-Zaleski I, Salloum R, Chawla N, Angiolini C, Crocetti E, Giusti F, Guzzinati S, Mezzetti M, Miccinesi G, Mariotto A. Comparing Cancer Care, Outcomes, and Costs Across Health Systems: Charting the Course. Journal of the National Cancer Institute Monographs 2013; 2013(46): 124-130.

40.Pater J, Rochon J, Parmar M, Selby P. Future research and methodological approaches. Annals of Oncology 2011; 22(Suppl 7): vii57-vii61.

41. Ronksley PE, McKay JA, Kobewka DM, Mulpuru S, Forster AJ. Patterns of health care use in a high-cost inpatient population in Ottawa, Ontario: a retrospective observational study. CMAJ Open 2015; 3(1): E111-E118.

42. Selby P, Autier P. The impact of the process of clinical research on health service outcomes. Annals of Oncology 2011; 22(Suppl 7): vii5-vii9.

43. Sundararajan V, Bohensky M, Moore G, Brand C, Lethborg C, Gold M, Murphy M, Collins A, Philip J. Mapping the patterns of care, the receipt of palliative care and the site of death for patients with malignant glioma. J Neurooncol 2014; 116(1): 119-126. 
44. Unrau YA, Wells MA. Patterns of foster care service delivery. Children and Youth Services Review 2005; 27(5): 511-531.

45. Yabroff KR, Francisci S, Mariotto A, Mezzetti M, Gigli A, Lipscomb J. Advancing Comparative Studies of Patterns of Care and Economic Outcomes in Cancer: Challenges and Opportunities. Journal of the National Cancer Institute Monographs 2013; 2013(46): 1-6.

46. Walsh C, Hripcsak G. The effects of data sources, cohort selection, and outcome definition on a predictive model of risk of thirty-day hospital readmissions. Journal of Biomedical Informatics 2014; 52: 418-426.

47. Carley KM .ORA: A Toolkit for Dynamic Network Analysis and Visualization. In: Alhajj R, Rokne J. (editors) Encyclopedia of Social Network Analysis and Mining. New York, NY: Springer; 2014.

48. Wasserman S, Faust K. Social Network Analysis: Methods and Applications. Cambridge: Cambridge University Press; 1994.

49. Carillo J, Carillo V, Guimento R, Murcaria J, Leiman J. The New York-Presbyterian regional health collaborative: A three-year progress report. Health Aff 2014; 33(11): 1985-1992.

50.Cunningham FC, Ranmuthugala G, Plumb J, Georgiou A, Westbrook JI, Braithwaite J. Health professional networks as a vector for improving healthcare quality and safety: a systematic review. BMJ Quality \& Safety 2012; 21(3): 239-249.

51.Porter SC, Forbes P, Feldman HA, Goldmann DA. Impact of patient-centered decision support on quality of asthma care in the emergency department. Pediatrics 2006; 117(1): e33-42.

52. Freeman LC. Centrality in social networks: Concept clarification. Social Networks 1979; 1: 215-239.

53. Pollack CE, Weissman GE, Lemke KW, Hussey PS, Weiner JP. Patient Sharing Among Physicians and Costs of Care: A Network Analytic Approach to Care Coordination Using Claims Data. Journal of general internal medicine 2013; 28(3): 459-465. 